\title{
CONSUMO ENERGÉTICO NO SISTEMA DE CAPTAÇÃO E BOMBEAMENTO DA ÁGUA CINZA
}

\author{
Gislana Santana'; Eduardo Cohim² \\ 1. Gislana Santana Machado PROBIC/UEFS, Graduando em Engenharia Civil, Universidade Estadual de Feira de \\ Santana, e-mail: gislanalsm@gmail.com \\ 2. Orientador: Eduardo Henrique Borges Cohim Silva, Departamento de Tecnologia, Universidade Estadual de Feira \\ de Santana, e-mail: edcohim@gmail.com
}

PALAVRAS-CHAVE: Água Cinza; Reúso; Energia.

\section{INTRODUÇÃO}

A energia dirige cada elemento do ciclo da água, enquanto a água é necessária para a produção de energia. A energia necessária para tratar a água a níveis aceitáveis está na faixa de 0,03-7 kWh/m³ , dependendo das fontes de água (água doce, água do mar, águas residuais) e parâmetros regionais específicos, como condições climáticas, disponibilidade de água, uso de água e densidade populacional. (LAZAROVA, 2012).

Para calcular a quantidade de energia proporcional a água consumida em residências, deve-se adotar estratégias que considerem a energia embutida tanto na água tratada e distribuída quanto no efluente coletado e tratado. Em prol do desenvolvimento sustentável, a infraestrutura do setor hídrico deve consumir menos energia e reduzir emissões de gases do efeito estufa (MACLEOD; FILION, 2011; BONTON et al., 2012).

O setor hídrico demanda elevada quantidade de energia utilizada para o bombeamento e o tratamento de água. Portanto, qualquer redução no consumo de água potável em edifícios pode resultar em uma redução da eletricidade para a empresa de água e esgoto (PROENÇA, 2011). Friedler e Lahav (2006) descrevem que com a adoção de sistemas de aproveitamento de água cinza em edificações, seus habitantes reduzem gastos com água e esgoto. O reúso de água cinza, que são águas provenientes de chuveiros, lavatórios e lavanderia, é feito após a separação destas águas das águas do vaso sanitário. Com a separação, a água cinza é direcionada para o local de tratamento.

Esse trabalho justifica-se pela busca por meios alternativos de reaproveitamento de água, no caso o reúso da água cinza, que interligado com o consumo de energia minimize os problemas ambientais. Busca-se analisar se a quantidade de energia gasta no sistema de reuso da água cinza é menor do que o consumo de energia utilizada pelo sistema de abastecimento de água na cidade de Feira de Santana/BA. Segundo Guanais (2015) o consumo energético no ciclo de vida do sistema de abastecimento de água na cidade de Feira de Santana - BA foi de 3,51 kWh/m3 de água efetivamente consumida.

\section{MATERIAL E MÉTODOS OU METODOLOGIA}

O projeto da estação de tratamento de águas cinza (ETAC) foi implantado numa unidade unifamiliar de alto padrão que localiza-se em Feira de Santana-Ba, no 
Condomínio Lagune Ville. A ETAC realiza o tratamento da água cinza, através de sistemas anaeróbios (Reator Anaeróbio Compartimentado - RAC) e sistema aeróbio (Filtro Intermitente Aeróbico- FIA).

Para avaliar a energia incorporada nesse sistema na produção de $1 \mathrm{~m}^{3}$ de água cinza tratada foi realizada uma ACV (avaliação do ciclo de vida), baseada na NBR ISSO 14044 (200a) e NBR ISSO 14044 (200b), sendo feita em quatro etapas: definição de objetivo e escopo, análise de inventário, avaliação do impacto e interpretação dos resultados.

O modelo aplicado é ACV atribucional, uma vez que o sistema avaliado pode ser observado/medido, e liga os processos individuais dentro da tecnosfera ao longo do fluxo de matéria, energia e serviços.

A partir da apropriação do objeto de estudo e do conhecimento dos temas estabeleceu-se a fase de objetivo e escopo da ACV com a definição da aplicação pretendida, da função do sistema, da unidade funcional, da fronteira do sistema e outros atributos.

\section{Escopo}

-Sistema estudado

O sistema estudado é a ETAC utilizada nesse trabalho.

-Unidade funcional

A unidade funcional adotada é de $1 \mathrm{~m}^{3}$ de água cinza tratada produzida.

-Fronteira do sistema

As fronteiras do sistema irão considerar a fabricação dos materiais que compõem a estação, transporte dos materiais, e o consumo de energia para funcionamento da ETAC, que possui o tempo de vida útil estimado em 25 anos.

Análise de inventário

Serão utilizados dados secundários do Ecoinvent ${ }^{\circledR}$ e para análise dos resultados será utilizado o Software SimaPro® 39.

Uma das entradas do inventário é a energia consumida $(\mathrm{kWh})$ no tratamento de água cinza e a quantidade de água produzida $\left(\mathrm{m}^{3}\right)$. Os dados foram obtidos diretamente através de medidores de energia e de água. $\mathrm{O}$ medidor de energia foi instalado entre o quadro de controle e a fonte de energia da estação. Já o hidrômetro (medidor de água) foi instalado num trecho da saída do filtro intermitente aeróbio para o reservatório da água cinza tratada.

Os dados de entrada no Software SimaPro® foi o peso necessário de cada material em $\mathrm{kg}$ para a fabricação dos componentes da estação. Os quais foram: fibra de vidro, resina de poliéster, concreto, geotêxtil, PVC, Aço e bomba.

\section{RESULTADOS E/OU DISCUSSÃO}

Na tabela 1 apresentada encontram-se os respectivos resultados obtidos no Software SimaPro®, a partir dos dados de entrada do inventário. 
Tabela 1. Energia Incorporada no Processo de Fabricação Dos Materiais e Consumo de Energia no Tratamento da Água Cinza

\begin{tabular}{|c|c|c|c|c|c|c|}
\hline Descrição & SimaPro® & Unidade & Quantidade & $\begin{array}{c}\text { Energia } \\
\text { Unitária } \\
(\mathbf{M J}) \\
\end{array}$ & $\begin{array}{l}\text { Total } \\
(\mathbf{M J})\end{array}$ & $\begin{array}{c}\text { Total } \\
\left(\mathbf{k W h} / \mathbf{m}^{3}\right)\end{array}$ \\
\hline \multicolumn{7}{|l|}{ Fibra de } \\
\hline Vidro & Glass Fibre $\{$ RoW $\}$ |production|Alloc Def, U & $\mathrm{kg}$ & 9,33 & 35,80 & 334,01 & 0,01017 \\
\hline Resina de & Polyester resin unsaturated & & & & & \\
\hline Poliéster & $\begin{array}{c}\{\mathrm{GLO}\} \mid \text { production|Alloc Def, U } \\
\text { Concrete, } 25 \mathrm{Mpa}\{\text { RoW }\} \mid \text { Concrete }\end{array}$ & $\mathrm{kg}$ & 27,98 & 114,00 & 3189,72 & 0,09710 \\
\hline Concreto & production $25 \mathrm{Mpa}$ & $\mathrm{m}^{3}$ & 0,05 & 1400,00 & 70,00 & 0,00213 \\
\hline Geotêxtil & $\begin{array}{l}\text { Polyester - complexed starck biopolymer } \\
\qquad\{\text { RoW }\} \mid \text { production }\end{array}$ & $\mathrm{kg}$ & 31,00 & 59,70 & 1850,70 & 0,05634 \\
\hline PVC & $\begin{array}{l}\text { PVC pipe }\{\text { RER }\} \mid \text { production|Alloc Rec, U } \\
\text { Stell, Low-alloyed, hot rolled }\{\text { GLO }\} \mid \text { Market }\end{array}$ & $\mathrm{kg}$ & 11,04 & 110,00 & 1213,96 & 0,03695 \\
\hline Aço & for & $\mathrm{kg}$ & 7,95 & 25,30 & 201,14 & 0,00612 \\
\hline Bomba & $\begin{array}{l}\text { Metal working machine, unespecified } \\
\qquad\{\mathrm{RoW}\} \mid \text { production }\end{array}$ & $\mathrm{kg}$ & 5,00 & 70,90 & 354,50 & 0,01079 \\
\hline Transporte & Total de transporte de to & os os mate & iais & & 357,00 & 0,01087 \\
\hline & Electricity, low voltage $\{\mathrm{BR}\} \mid$ market for $\mid$ & & & & & 251078 \\
\hline
\end{tabular}

Legenda. Dados obtidos pelo Software SimaPro® 39

O consumo energético total no ciclo de vida da ETAC, considerando uma vida útil de 25 anos e sabendo que produz $1 \mathrm{~m}^{3}$ por dia, foi de $2,74 \mathrm{kWh} / \mathrm{m}^{3}$, com a soma de todos os consumos da tabela 1 .
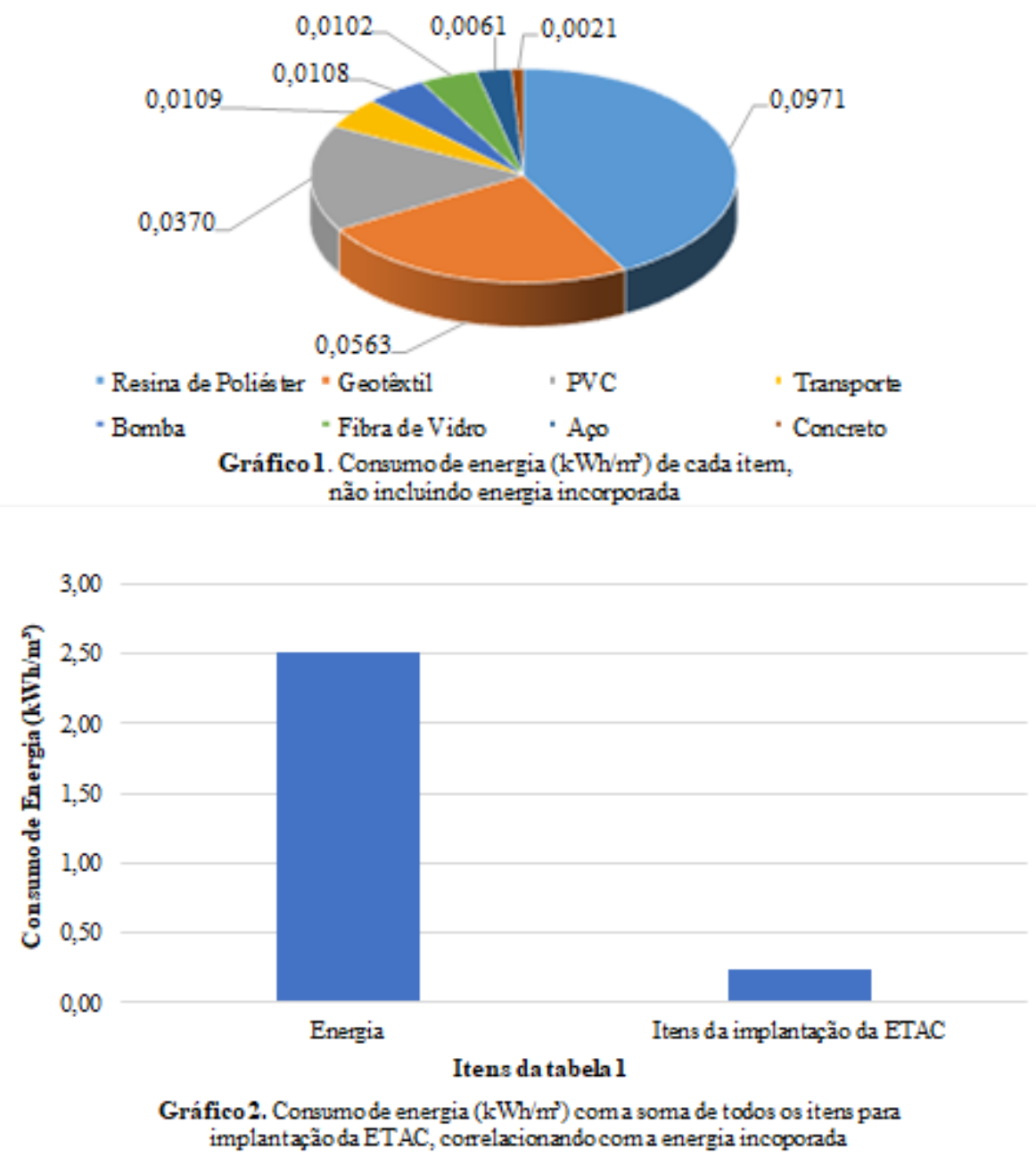
De acordo com o gráfico 1, não levando em consideração a energia incorporada no funcionamento da ETAC, pode-se observar que a resina de poliéster é o material, dentre todos os demais citados, que causa o maior consumo de energia, e o concreto o que causa menor consumo. No gráfico 2, considerando a energia incorporada, e comparando com a soma do consumo de energia de todos os demais itens, que é $8,4 \%$ do consumo total, pode-se analisar que a energia elétrica utilizada para o funcionamento da ETAC é o que gera o maior consumo energético, com $91,6 \%$ do total.

\section{CONCLUSÃO}

Tendo em vista a energia incorporada no sistema como uma forma de avaliar o impacto ambiental, o setor de água tem buscado diminuir o consumo de energia e energia incorporada no sistema de tratamento de água. Com isso, foi feita a avaliação do consumo energético da ETAC, localizada numa residência de alto padrão em Feira de Santana-Ba, para produzir $1 \mathrm{~m}^{3}$ de água cinza durante seu ciclo de vida, com relação ao consumo gasto no sistema de abastecimento da cidade de Feira de Santana-Ba para produzir $1 \mathrm{~m}^{3}$ de água potável durante seu ciclo de vida.

Segundo GUANAIS (2015) o consumo energético total no Ciclo de Vida do tratamento do SIAA-FSA (Sistema de Abastecimento de Água) foi de $3,51 \mathrm{kWh} / \mathrm{m}^{3}$ de água efetivamente consumida. Logo, ao comparar esse resultado com o $2,74 \mathrm{kWh} / \mathrm{m}^{3}$, que foi o obtido pela estação de tratamento de água cinza, pode-se dizer que a ETAC é um projeto viável e possui uma eficiência de $22 \%$. No entanto, não há uma diferença considerável para que possa considerar a ETAC como melhor forma de tratamento para o reúso de água, em prol de diminuir o consumo de energia.

\section{REFERÊNCIAS}

BONTON, A.; BOUCHARD, C.; BARBEAU, B.; JEDRZEJAK, S. Comparative life cycle assessment of water treatment plants.Desalination, v. 284, n. 1, p. 42-54, Elsevier, 2012.

FRIEDLER, E.; LAHAV, O. Centralised urban wastewater reuse: what is the public attitude? Water Science and Technology, v. 54, n. 6-7, p. 423-430, IWA Publishing, 2006.

GUANAIS, Ana Luiza da Silva Rezende et al. Avaliação energética e das emissões de gases de efeito estufa do Sistema Integrado de Abastecimento de Água de Feira de Santana. Dissertação. Universidade Estadual de Feira de Santana, 2015. LAZAROVA, Valentina; CHOO, Kwang-Ho; CORNEL, Peter (Ed.). Water-energy

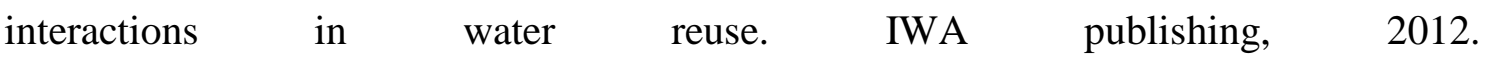
MACLEOD, S. P.; FILION, Y. R. Issues and Implications of Carbon-Abatement Discounting and Pricing for Drinking Water System Design in Canada. WaterResources Management, v. 26, n. 1, p. 43-61, Springer, 2011. PROENÇA, L. C.; GHISI, E.; TAVARES, D. DA F.; COELHO, G. M. Potential for electricity savings by reducing potable water consumption in a city scale. Resources, Conservation and Recycling, v. 55, n. 11, p. 960-965.Elsevier, 2011. 